\title{
Evolução recente da indústria em países latino-americanos selecionados: uma análise do processo de desindustrialização para o período de 2000-2014
}

\author{
Recent evolution of industry in selected latin american countries: an analysis of the \\ disindustrialization process for the period 2000-2014
}

\section{Antônio Paulo da Silva Mesquita Junior ${ }^{I}$}

\begin{abstract}
Resumo
Este trabalho trouxe à discussão a indústria de países latino-americanos selecionados - Brasil, Argentina, México e Chile -, no período de 2000 a 2014, com propósito de indicar se esta vem, ou não, passando por inflexões contingenciadas ao processo de desindustrialização. Para tal, foi realizada uma análise empírica que examinou o comportamento da participação relativa do valor adicionado da indústria no PIB, do emprego industrial no emprego total e da balança comercial. Através da análise, pôde-se constatar que esses países vêm passando por um processo de desindustrialização precoce e heterogêneo.
\end{abstract}

Palavras-chave: Indústria; Desindustrialização; Países latino-americanos

\begin{abstract}
This study brought into discussion the industry in selected latin american countries, Brazil, Argentina, Mexico and Chile, encompassing the period of 2000 to 2014 , with the purpose to indicate if the industry is passing through inflections contingent to the process of deindustralization. With this objective, an empirical analysis was realized, that examined the behaviour of the relative share of industry value added in GDP, the industrial employment in total employment and trade balance. Through this analysis, it can be seen that these countries are undergoing an early and heterogeneous process of deindustralization.
\end{abstract}

Keywords: Industry; Deindustralization; Latin American Countries 


\section{Introdução}

O início do processo de industrialização dos países latino-americanos se deu de forma lenta e retardatária. Diferente da Inglaterra que encetou a transformação de sua estrutura produtiva ainda no século XVIII, na América Latina a industrialização teve início somente no século XX, sendo resultado de uma gama de mudanças que ocorreram no mundo, nos âmbitos econômico e político, tendo a crise de 29 como a "cereja de bolo".

A emersão da indústria nessa região foi nucleada pelo Processo de Substituição de Importações ${ }^{1}$ (PSI), que criou parte do arcabouço necessário para o desenvolvimento do setor. No Brasil, Argentina e México, o PSI foi mais intenso e se deu em função, sobretudo, da queda cavalar na capacidade de importar somada a significativa capacidade instalada ociosa. No Chile, porém, o processo de industrialização teve como base a ação estatal no plano econômico, de tal maneira que o PSI apresentou papel coadjuvante nesse caso (FURTADO, 1969).

Tendo a configuração da base industrial de 1929 como ponto de partida, nota-se uma significativa heterogeneidade na industrialização desses países ${ }^{2}$, também observada no período de crescimento industrial que se deu em função dos estímulos da primeira guerra, responsável pelo desenvolvimento de um incipiente setor de bens de capital, em especial no Brasil e no Chile. Nos casos do México e da Argentina, esse crescimento foi retardado, respectivamente, pelos fortes laços comerciais com os EUA, que estimulavam as importações, junto aos significativos problemas internos, e pelas colheitas ruins no transcorrer da primeira guerra (TRHOP, 1998).

A conformação de uma estrutura industrial é um ponto fundamental para o desenvolvimento das economias latino-americanas (FURTADO, 1982). Isso porque, enquanto exportadoras de produtos primários, essas não são capazes de comandar seu próprio desenvolvimento, dependendo, em última instância, da demanda oriunda dos países centrais. Esses, por sua vez, assumem o papel de produzir bens industrializados. A dinâmica desse comércio tende a aprofundar o desenvolvimento desigual entre o centro e a periferia.

A presença da indústria na estrutura produtiva dessas economias teria, portanto, o papel de constituir engrenagens que viessem a reduzir a dependência em relação aos países centrais e, assim, possibilitar um desenvolvimento endógeno, rompendo com a lógica das vantagens comparativas ricardianas. Sob essa lógica, as economias latino-americanas estariam fadadas a especialização primário-exportadora, em virtude da abundância interna de recursos naturais, que as impossibilita de usufruir dos reais frutos tecnológicos decorrentes do comércio internacional. Prebisch (1962) aponta que, diferente do que é pregado pela vertente ricardiana, os frutos do comércio responsáveis pelo aumento da produtividade não são simetricamente distribuídos, concentrando-se majoritariamente nos países centrais, o que deteriora os termos de troca da periferia.

Nos últimos anos, os debates em torno do processo de industrialização, bem como de sua importância, sobretudo para as economias latino-americanas, foram reiterados. Agora, em uma perspectiva diferente da observada nas décadas precedentes a de 90 , a discussão centra-se na reversão desse processo - a desindustrialização - e nos perversos impactos à sociedade quando esse fenômeno ocorre precocemente.

A desindustrialização é o processo no qual a indústria passa a perder representatividade na economia de determinada região ou país. Filgueiras (2012) aponta que nos casos em que esse processo ocorre precocemente, a indústria passa a perder força na economia antes de ter seu círculo de desenvolvimento concluído, o que tende a afetar negativamente à sociedade, em decorrência dos efeitos nocivos sobre os níveis de emprego e renda.

Diante disso, este trabalho prontificar-se-á de analisar a evolução recente da indústria de países latino-americanos selecionados - Brasil, México, Chile e Argentina - por meio do exame de indicadores industriais, a se dizer: valor adicionado da indústria no PIB, participação relativa do emprego industrial no emprego total e a balança comercial de bens industrializados. A análise permitirá indicar se a estrutura produtiva desses países vem, ou não, passando inflexões contingenciadas ao processo de desindustrialização, no período de 2000 a 2014. A hipótese é que houveram mudanças que reduziram a participação da indústria na economia desses países.

O artigo contará com 4 seções, além dessa abordagem introdutória. A seção 1 apreenderá questões relacionadas ao conceito, as possíveis causas e a configuração dos diferentes tipos de desindustrialização. A seção 2 contará com breves considerações em torno do debate do processo de desindustrialização na América Latina. A análise empírica do processo de desindustrialização nos países selecionados será realizada na seção 3. O exame dos indicadores industriais trará elementos que permitirão indicar se essas economias vêm, ou não, se desindustrializando. Por fim, a quarta (e última) seção contemplará as considerações finais.

\footnotetext{
1 A crise cria condições necessárias para o PSI: I) o cenário recessivo mundial leva a uma queda na demanda e, assim, nos preços dos bens exportados pela periferia, o que induz a adoção de políticas de desvalorização cambial, de modo a encarecer as importações; II) adoção de políticas de anticíclicas, que gera um efeito renda e acarreta na redução dos juros, aumentando os investimentos e estimulando o desenvolvimento da indústria doméstica. Sobreleva-se que o PSI não deve ser visto como um mero processo em que o país passa produzir internamente o que antes era importado. O objetivo do processo é tornar o setor industrial o líder do crescimento econômico, de modo a aumentar o dinamismo da economia e, assim, de gerar maiores níveis de emprego e renda (FONSECA, 1999).

2 Ver Thorp (1998)
} 


\section{Desindustrialização: conceito e causas em diferentes perspectivas}

As significativas mudanças estruturais nas economias latino-americanas decorrentes da adoção de políticas de cunho neoliberal, sobretudo a partir dos anos 90 , trouxeram consigo recorrentes debates em torno do processo de reestruturação produtiva, em especial no que tange o processo de desindustrialização. As questões associadas a precocidade desse processo em alguns países e aos seus respectivos impactos sobre a sociedade ficaram situadas no centro do debate, isso porque, em última instância, traduzem-se em variações negativas nos níveis de emprego e de renda.

Por desindustrialização entende-se o processo de reestruturação produtiva que comprime a participação do setor industrial. Para Rowthorn e Ramaswany (1999), esse processo evidencia-se pela queda da participação do emprego industrial no emprego total, que representa a perda da importância do setor industrial na economia. Tregenna (2009) aponta que, para além das variações nessa relação, o comportamento da relação entre o valor adicionado da indústria e o PIB deve ser considerado. Dessa maneira, junto a queda do emprego industrial no emprego total, a redução da participação do valor adicionado da indústria no PIB contribui com a hipótese de que a economia está passando por um processo de desindustrialização.

Por vezes, a compressão da participação da indústria na economia está associada a uma fase avançada do processo de desenvolvimento econômico, esse é o caso desindustrialização natural. Segundo DIEESE (2011), o processo de desindustrialização natural pode ser encarado como um processo de sofisticação das economias. Essa perspectiva tem como base estudo realizado por Clark (1957). Segundo o autor, à medida que as sociedades vão se desenvolvendo a elasticidade renda da demanda dos indivíduos vão se alterando. Assim, no primeiro momento, os países são especializados na produção de bens primários e apresentam um baixo nível de renda per capita. A medida que vão se desenvolvendo, e elevando o nível de renda, a especialização se volta para o setor industrial, que passa a representar a maior proporção no PIB. Nesse momento, a elasticidade renda da demanda por produtos industrializados é ligeiramente maior que 1. No momento seguinte, ao atingirem elevados níveis de renda, a elasticidade por produtos industriais, anteriormente ligeiramente maior que 1, passa a ser ligeiramente menor que 1, resultando no crescimento do setor de serviços em detrimento do setor industrial. Destarte, o processo de desindustrialização natural é visto como um nível avançado do processo de desenvolvimento das economias.

Todavia, em outros casos, a perda de representatividade da indústria na economia se dá em função de fatores negativos, não estando, portanto, associada ao processo de desenvolvimento das economias. Esse é o caso da desindustrialização precoce.

Em contraste ao natural, o processo de desindustrialização precoce apresenta perversos efeitos à sociedade, sendo, segundo Fishlow (2013), a real ameaça ao desenvolvimento. Isso porque a indústria passa a perder espaço na estrutura produtiva antes do país/região alcançar elevados níveis de renda per capita, produtividade e competitividade internacional. Com isso, a desindustrialização tende a reduzir o nível de renda e da qualidade dos empregos, reduzindo, de modo geral, a qualidade de vida da sociedade (NASSIF, 2008).

Por outro lado, o comportamento do setor externo também traz elementos que contribuem na análise do processo de desindustrialização. Na verdade, as variações na pauta exportadora e na balança comercial dos setores colaboram para o exame simultâneo do processo de desindustrialização e de reprimarização. A ideia é de que a expansão da participação de commodities na pauta exportadora, em detrimento de bens mais intensivos em tecnologia, está fortemente associada a ocorrência desse duplo processo, que tende a estimular superávits na balança de commodities e déficits na balança dos bens mais tecnologicamente enriquecidos. Este quadro, por vezes, emerge em função do comportamento da taxa de câmbio. Palma (2005) aponta que a perda da representatividade do setor industrial em determinada economia pode ser reflexo da doença holandesa ${ }^{3}$, que reduz significativamente a competitividade do setor industrial doméstico frente à concorrência internacional e estimula a inserção regressiva à medida que potencializa a competitividade das commodities, que se mostram compatíveis com as apreciadas taxas cambiais.

A desindustrialização, nesse contexto, é classificada por Oreiro e Feijó (2010) como negativa, à medida que reflete um "processo de reversão da pauta exportadora na direção de commodities, produtos primários ou manufaturas com baixo valor adicionado e/ou baixo conteúdo tecnológico". (Oreiro e Feijó, 2010, p. 222).

Analogamente, quando o processo se configura positivo, a redução da participação da indústria na estrutura produtiva é derivada da transferência para o exterior de atividades industriais mais intensivas em trabalho e ocorre junto ao aumento da participação de produtos mais intensivos em capital e com maior valor tecnológico na pauta exportadora.

Os impactos das políticas de ajuste também devem ser considerados na pauta do processo de desindustrialização. Sobretudo em momento de estagnação, a política econômica tende a impactar fortemente na composição da estrutura produtiva à medida que cria arcabouços que favorecem o desenvolvimento de determinados setores, enquanto deterioram a evolução de outros. A adotada nos países latino-americanos no transcorrer da década de 90, que tinha como base a ortodoxia econômica, por exemplo, ao mesmo tempo que comprimiu os segmentos industriais mais intensivos em tecnologia, alavancou os produtores de commodities em virtude das vantagens comparativas apresentadas pelos países dessa região, que preservaram a competitividade destes segmentos mesmo frente a combinação juros elevado e câmbio apreciado.

\footnotetext{
3 Também conhecida como "maldição dos recursos naturais", a doença holandesa foi pioneiramente observada nos países baixos, em especial na Holanda, ainda na década de 60. Essa pode ser entendida como uma falha de mercado estrutural decorrente da abundância e baixos preços dos recursos naturais em determinada região, o que tende a apreciar cronicamente a taxa de câmbio, de modo a comprometer o setor industrial.
} 
Nesse contexto, a orientação tomada pela política econômica torna-se incompatível com as políticas industriais ${ }^{4}$. Assim, ao invés de criar um ambiente propício para a implementação de políticas de cunho setorial e, consequentemente, para o desenvolvimento do setor industrial, a política econômica tende a retardar, ou mesmo anular, seus efeitos. Esse é o caso das "sadias" políticas macroeconômicas indicadas pelas agências multilaterais.

Em especial nos casos em que as vantagens competitivas não são observadas no setor industrial, as políticas industriais evidenciam-se fundamentais. Isso porque, considerando a perspectiva kaldoriana, a adoção dessas políticas torna-se uma condição para o crescimento das economias, em virtude do papel que possuem no processo de desenvolvimento industrial. Kaldor (1966) aponta a indústria como o motor do crescimento, em decorrência dos rendimentos crescentes de escala e do forte efeito encadeamento produtivo, a montante e a jusante, observados no setor, que estimulam a economia aumentando os níveis de emprego e renda, a competência tecnológica e a competitividade das empresas. Em uma perspectiva mais recente, o argumento central é o de que determinados segmentos industriais tendem a gerar externalidades locais responsáveis por aumentar o dinamismo em termos de inovação e tecnologia, o que gera transbordamentos para além das empresas, como o caso do Vale do Silício na Califórnia (SCHYMURA E PINHEIRO, 2013).

Em suma, o fenômeno da desindustrialização, que pode ocorrer de forma natural ou precoce, evidencia-se por meio de respostas negativas de alguns indicadores industriais a mudanças nos mais diversos âmbitos que são nocivas ao setor. Políticas econômicas que resultam no aumento significativo da taxa de juros e na forte apreciação cambial, bem como deficientes políticas industriais, entram no quadro de medidas que pressionam negativamente a participação do setor industrial na economia.

\section{O debate da desindustrialização na américa latina}

Os debates em torno do possível processo de desindustrialização que as economias latino-americanas vêm passando são nucleados por divergências em relação a sua precocidade, bem como de suas causas. A hipótese Cepalina é de que essas economias estão passando por um processo de desindustrialização progressivo e prematuro. O argumento se fundamenta, sobretudo, na posição do nível de renda e na produtividade desses países. Por um lado, enquanto a contração da indústria na economia passou a apresentar sinais em um momento em que a renda per capita desses países era consideravelmente baixa em relação aos países desenvolvidos. Por outro, os serviços que passaram a expandir a participação na economia apresentavam níveis de produtividade inferiores aos observada no setor industrial.

O efeito negativo do processo desindustrialização sobre a produtividade é assinalado por Schymura e Pinheiro (2013). Segundo os autores, em diversos casos, como o da América Latina, a desindustrialização evidencia-se potencialmente danosa em decorrência de dois efeitos principais que esse processo tende a causar:

1. Efeito composição - Com a desindustrialização os trabalhadores são deslocados para setores com diferentes níveis de produtividade. No caso dos países latino-americanos, a mão de obra tende a ser alocada para setores com menor produtividade, como o de serviços, que leva a redução da produtividade do país como um todo. Esse processo pôde ser observado principalmente a partir do processo de abertura comercial na década de 90;

2. Efeito encadeamento - A indústria é o setor que possui maior capacidade de aumentar o dinamismo da economia como um todo, sendo responsável por expandir a oferta de postos de trabalho ${ }^{5}$ em outros setores à medida que demanda insumos de diversos segmentos, tendo o setor automobilístico como exemplo clássico. Diante disso, o processo de desindustrialização viria a reduzir os encadeamentos produtivos, de modo a tornar a economia menos dinâmica, afetando negativamente o nível de emprego.

Os resultados negativos intrínsecos ao processo de desindustrialização precoce possuem forte associação com a configuração estrutural das economias. Além do baixo nível de renda per capita, a baixa capacidade do setor de serviços de ofertar postos de trabalho com elevadas remunerações e alta produtividade, bem como a tendência à especialização na produção de bens de baixo valor agregado, tornam o processo de desindustrialização um desafio.

Nesses casos, à medida que a indústria perde importância na economia, as commodities e os produtos de baixo valor agregado tendem a expandir a participação nas exportações, acarretando, portanto, em uma simultânea reprimarização da pauta exportadora. Os efeitos negativos desse padrão de especialização são diversos. As condições de trabalho e o poder aquisitivo dos trabalhadores são significativamente deteriorados devido a posição que os assalariados passam a ocupar. Como maior

4 Por política industrial entende-se um conjunto de medidas adotadas visando o desenvolvimento industrial. Essas tendem a impossibilitar, ou pelo menos retardar, o processo de desindustrialização. São considerados parte da política industrial os seguintes elementos: "planejamento geral indicativo, formalização de diretrizes e objetivos, organização institucional especifica, articulação com a política macroeconômica, targeting de indústrias e tecnologias específicas, instrumentos e políticas auxiliares (políticas de comércio exterior, financiamento, políticas de fomento, políticas de regulação e competição), investimentos em infraestrutura econômica e de ciências e tecnologia, sistema educacional e treinamento de mão-de-obra e formação de recursos humanos especializados." (Suzigan, 1995, p. 6)

5 Não há consenso em relação a concepção de que quanto maiores os encadeamentos produtivos, maiores serão as ofertas de postos de trabalho. O argumento de Najberg e Vieira (1997) é de que, por vezes, setores que apresentam menores encadeamentos produtivos são responsáveis por gerar um maior número de empregos, tendo o setor de calçados como principal exemplo. 
parte da produção é destinada ao mercado externo, os trabalhadores não são considerados um elemento dinâmico no processo de acumulação. Consequentemente, o baixo nível salarial não os permite ter acesso aos produtos manufaturados (MOREIRA E MAGALHÃES, 2014; OSÓRIO, 2014).

Bielschowsky (2012) ressalta outros fatores que são nocivos ao processo de reprimarização:

1. A relevante possibilidade de algumas potências mundiais comprarem terras e acesso a fontes de energia e metais;

2. As pressões que a demanda por recursos naturais exerce sobre a natureza e a sustentabilidade ambiental, debate fortalecido pela crescente agenda de desenvolvimento sustentável;

3. A população é pouco contemplada com as tendências de valorização dos bens primários, sendo majoritariamente absolvida pelo setor privado, o que impossibilita o emprego de dividendos para educação e inovação, por exemplo.

Em última instância, com base nos significativos efeitos negativos sobre a dinâmica e desenvolvimento das economias, os impactos do processo de reprimarização podem ser reduzidos as mudanças sobre a capacidade inovativa e o encadeamento produtivo, que são fortemente contraídos devido a compressão dos segmentos industriais mais intensivos em tecnologia.

\section{Análise empírica do processo de desindustrialização nos países selecionados}

Mediante aos recorrentes debates em torno da possível inflexão da estrutura produtiva dos países selecionados no sentido da desindustrialização, essa seção prontificar-se-á de analisar empiricamente o comportamento do setor industrial. A análise permitirá concluir se as indústrias desses países vêm, ou não, sendo contingenciadas a desindustrialização. O exame terá como base o comportamento de indicadores industriais (adicionado da indústria, emprego industrial e comércio internacional) no transcorrer do período considerado neste estudo.

Paralelamente, a análise trará elementos que permitirão concluir se a evolução da indústria nesses países vem dando de forma homogênea, diferente do que foi observado no início do processo de industrialização.

\subsection{O valor adicionado da indústria no PIB: análise na perspectiva de Tragenna}

$\mathrm{Na}$ análise do processo de desindustrialização, a participação do valor adicionado da indústria no PIB aparece como um relevante indicador (TREGENNA, 2009). O argumento é de que a queda nessa relação representa um forte sinal de que o fenômeno da desindustrialização vem ocorrendo, em virtude da perda do peso da indústria na dinâmica econômica. Os gráfi$\cos 1,2,3$ e 4, mostram o comportamento do valor adicionado relativo da indústria total e da indústria de manufaturados dos países selecionados.

A evolução dos dados, sobretudo da indústria manufatureira, traz evidências que confirmam a hipótese de que essas economias vêm se desindustrializando, mas em diferentes níveis. Ao comparar a diferença entre o valor máximo e o mínimo do México e do Chile, por exemplo, observa-se que enquanto a participação no PIB deste primeiro manteve relativa estabilidade, com um hiato de 4 pontos percentuais, no segundo essa diferença foi quase 3 vezes maior. A partir da tendência de queda encetada em

Gráfico 1 - Valor adicionado da indústria em relação ao PIB do Brasil (2000-2014)

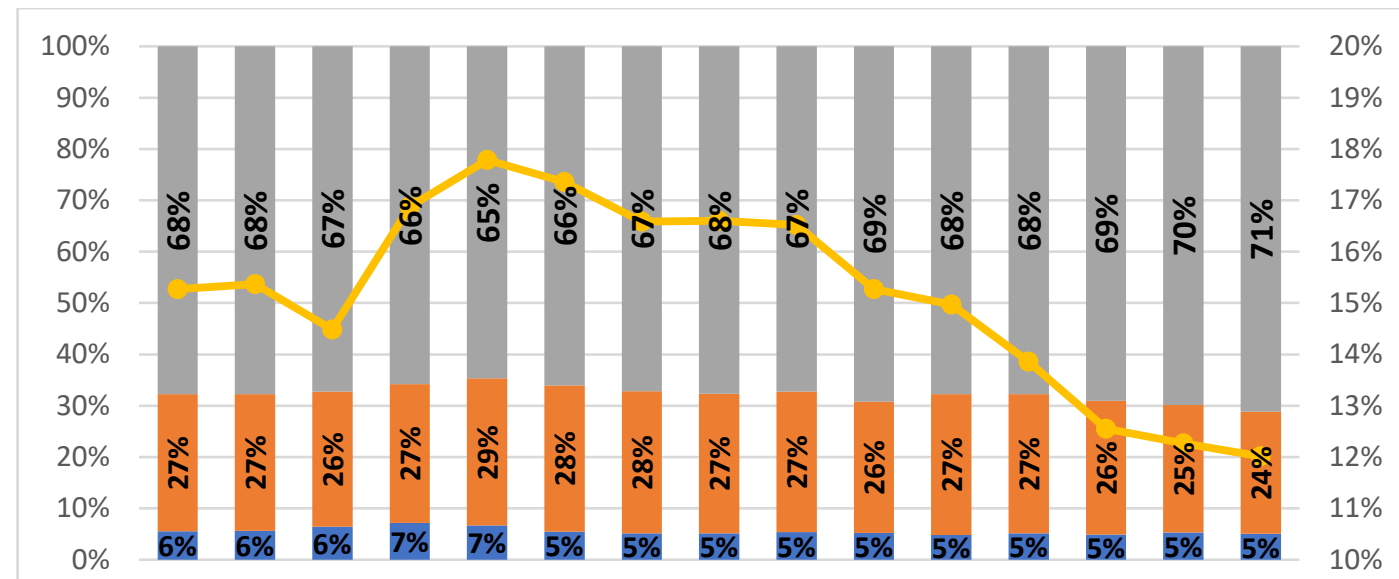

200020012002200320042005200620072008200920102011201220132014

Agricultura Industria $\quad$ Serviços $\quad$ Manufaturas

Fonte: Elaborado pelo autor a partir dos dados do World Development Indicators. 
Gráfico 2 - Valor adicionado da indústria em relação ao PIB da Argentina (2000-2014)

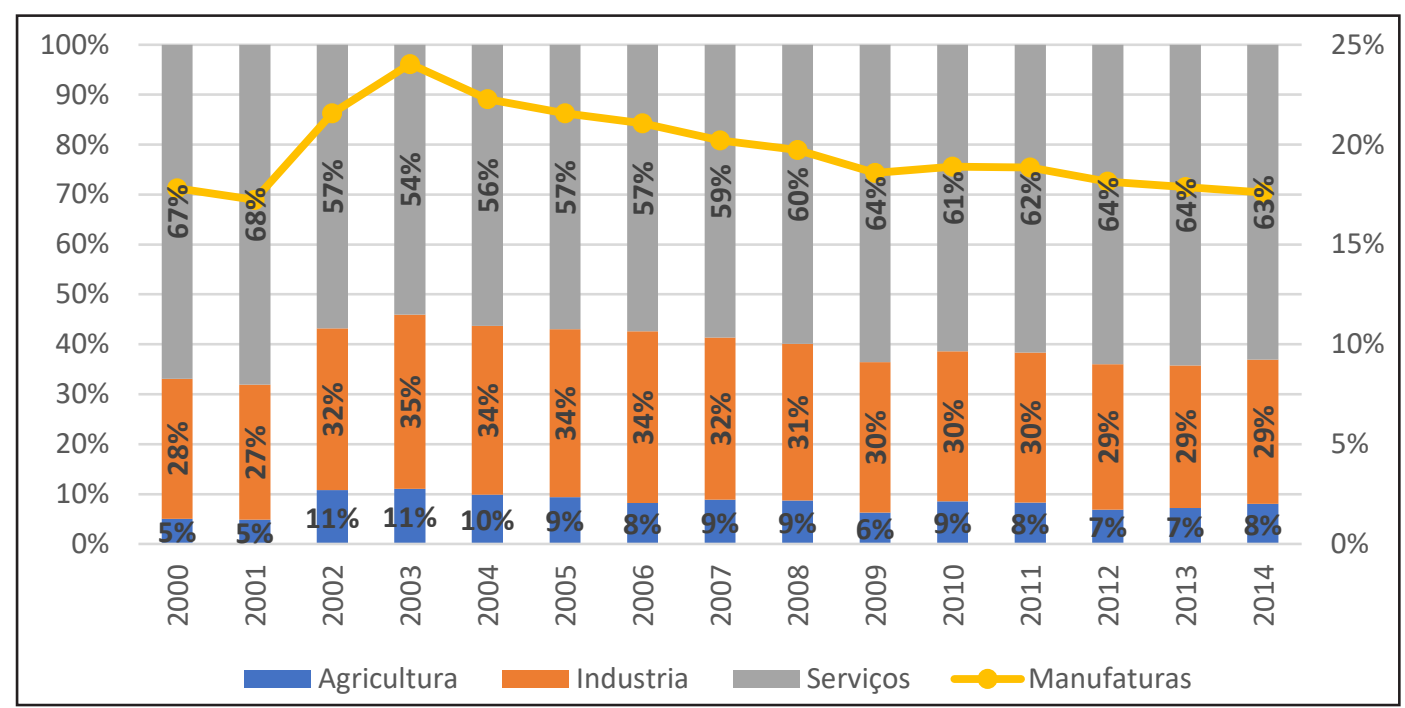

Fonte: Elaborado pelo autor a partir dos dados do World Development Indicators

Gráfico 3 - Valor adicionado da indústria em relação ao PIB da Chile (2000-2014)

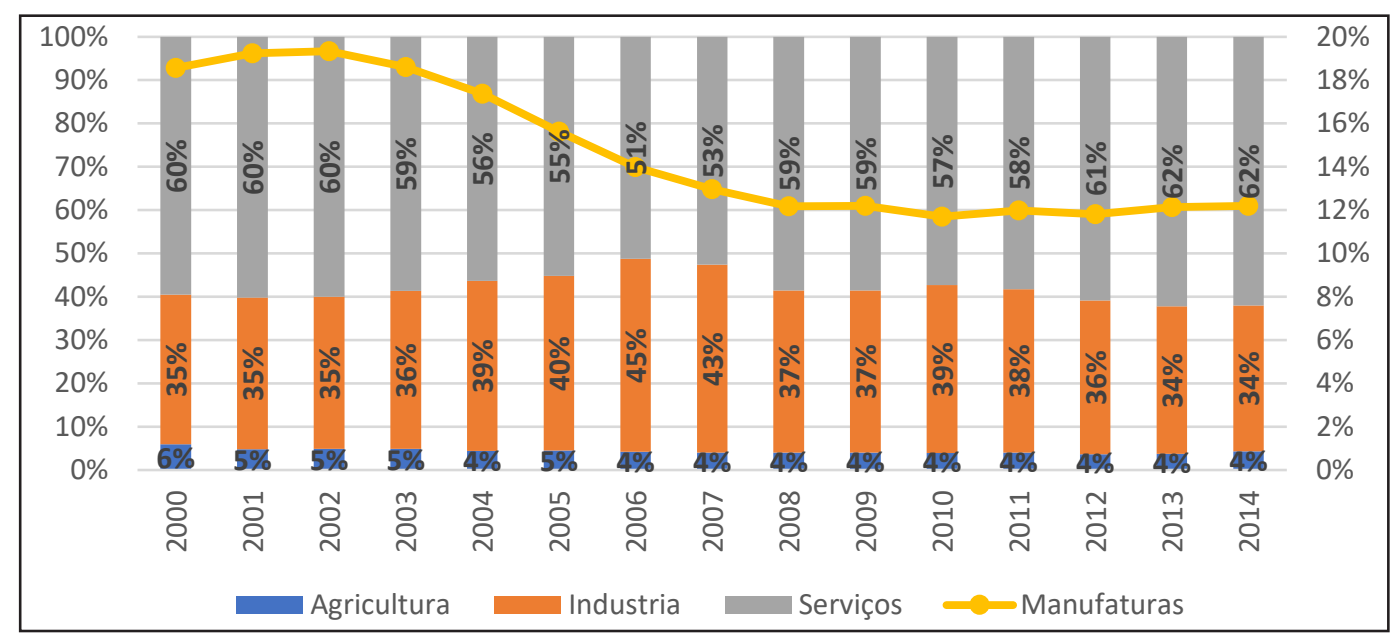

Fonte: Elaborado pelo autor a partir dos dados do World Development Indicators

Gráfico 4 - Valor adicionado da indústria em relação ao PIB do México (2000-2014)

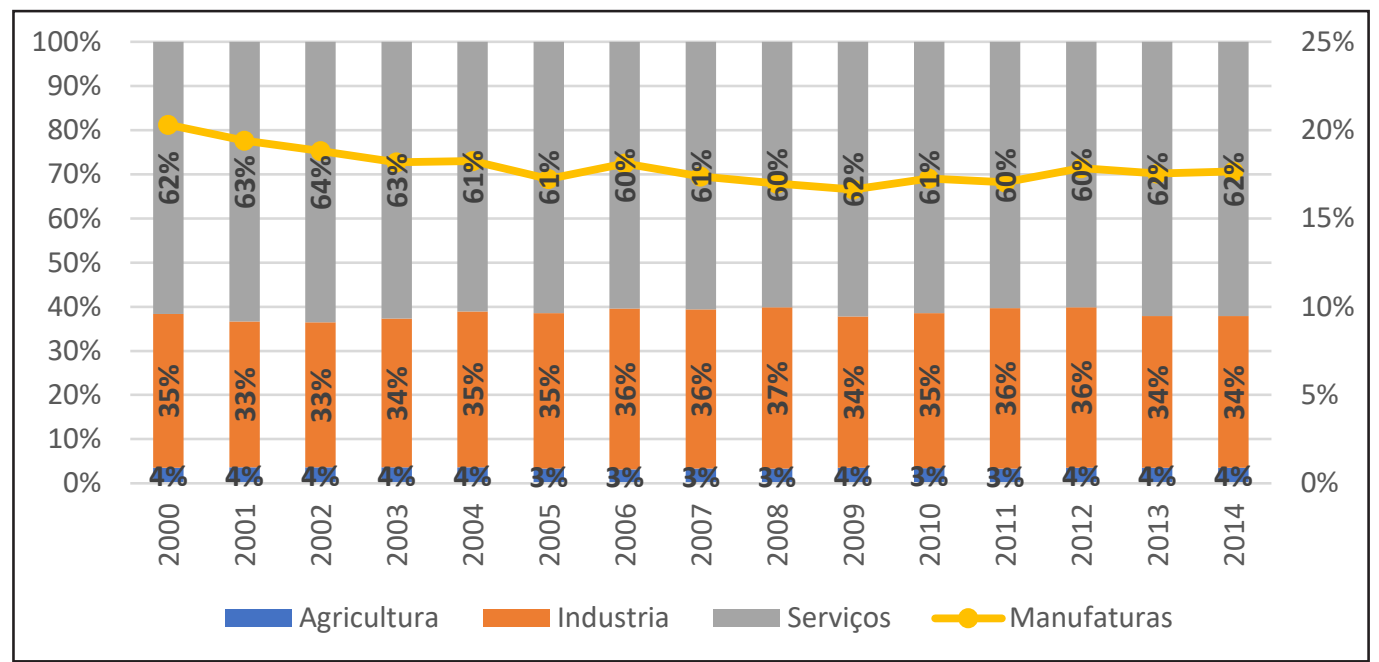

Fonte: Elaborado pelo autor a partir dos dados do World Development Indicators 
2006, o valor adicionado da indústria chilena reduziu sua participação no PIB em 11 pontos percentuais até 2014. No Brasil e na Argentina, essa diferença foi de 5 e 8 pontos percentuais, respectivamente, mas de forma contrária aos demais países, o valor adicionado da indústria na Argentina, em 2014, foi 1 ponto percentual maior do que o observado no ano-base da análise, isso porque somente após crescer 7 pontos percentuais entre 2000 e 2003 , a indústria argentina passou a perder representatividade na participação do produto, comprimindo sua parcela em 6 pontos percentuais a partir de então.

No Brasil, México e Chile, a queda teve início em 2004, 2008 e 2006, respectivamente. Nos dois primeiros casos, apesar do "saldo negativo" em relação ao ano-base, a tendência a queda não foi tão acentuada como na indústria argentina. Em contrapartida, a indústria desses países não apresentou o nível de crescimento como observado na indústria argentina no início dos anos 2000. No Chile, apesar da significativa expansão até 2006 (aumento de 10 pontos percentuais), a tendência a queda a partir de então, se deu de forma mais acentuada, de maneira que em 2014 a participação do valor adicionado da indústria chilena era 1 ponto percentual inferior ao observado no ano-base e 11 pontos percentuais menor que o observado em 2006.

Ao circunscrever a análise a indústria manufatureira, que apesar da forte heterogeneidade possui os segmentos mais importantes da estrutura produtiva, a queda evidencia-se ainda mais acentuada. A maior intensidade das variações negativas na indústria manufatureira se traduz em perdas ainda mais significativas a economia, em virtude da relevância em termos de dinâmica intrínseca a parte dos setores que a compõe.

No Brasil, a compressão dos segmentos mais intensivos em tecnologia se deu em função de algumas políticas que impulsionaram a demanda por produtos básicos - aumento do crédito e do salário mínimo, e as políticas de transferências de renda - e possibilitaram a inserção no mercado interno de parte da população que anteriormente encontrava-se fora dessa dinâmica. Destarte, a expansão cavalar nessa demanda foi responsável por estimular o desenvolvimento dos segmentos produtores de bens de baixo valor tecnológico, sobretudo de bens de consumo não duráveis, que passaram a crescer em detrimento dos segmentos mais intensivos em tecnologia.

Analogamente, os estímulos oriundos do mercado internacional contribuíram para essa evolução. A partir de 2004, diferente da tendência observada, em última análise, nas décadas precedentes, houve uma mudança positiva nos termos de troca, que foi acompanhada por uma significativa expansão da demanda por produtos primários e pela forte elevação nos preços das commodities. O favorável cenário internacional alavancou os investimentos, e respectivamente a expansão na estrutura produtiva, dos setores menos favorecidos tecnologicamente.

De modo geral, assim como nos demais países, apesar da tendência decrescente, a redução do valor adicionado da indústria brasileira não se deu de forma contínua. No biênio de 2010-2011, observa-se uma breve recuperação da indústria brasileira, o que pode ser visto como resultado das políticas de incentivo ao consumo de produtos industriais ${ }^{6}$, em especial aos bens de consumo duráveis, mas essa não prevaleceu, de modo que a partir de 2012 o valor adicionado da indústria no Brasil voltou a cair.

Dentre os países selecionados, o México foi o que apresentou as menores variações relativas no valor adicionado da indústria total e da manufatureira, que, modo geral, se mantiveram relativamente estáveis. Esse resultado é reflexo da presença das maquiladoras ${ }^{7}$ que sustentaram a participação do setor industrial no produto, omitindo as implicações ${ }^{8}$ da desindustrialização. Ainda assim, observa-se uma leve tendência a queda a partir de 2008, em função da crise do subprime. Tendo em conta que parte majoritária (cerca de 80\%) das exportações do México são destinadas aos EUA e que, após o NAFTA, cerca de $90 \%$ dos insumos utilizados nas maquiladoras passaram a ser importados sobretudo dos EUA, mudanças na economia norte-americana impactam diretamente no desempenho da indústria mexicana. O resultado evidencia que os fortes laços comerciais entre o México e os EUA observados no início do processo de industrialização foram conservados.

Contate-se, portanto, que a economia mexicana vem passando por um processo de desindustrialização, mas não de forma tão acentuada como os demais países. Cypher (2011) argumenta que esse processo vem sendo estimulado pela presença das maquiladoras na estrutura produtiva, que enfraquecem a indústria local devido ao elevado coeficiente de importação em seus produtos.

Em suma, foi possível observar uma redução da participação do valor adicionando da indústria no PIB dos países selecionados, que foi não contínua e teve diferentes níveis de perda. Essa inflexão pode ser considerada reflexo da onda neoliberal que passou a nuclear a política econômica desses países. A primazia pela estabilidade estimulou a apreciação cambial e deixou em segundo plano as políticas setoriais, como a industrial, o que reduziu a competitividade do setor industrial, sobretudo manufatureiro, dos países latino-americanos.

\footnotetext{
6 Nos últimos anos do governo Lula aforam adotadas políticas de incentivo ao consumo de produtos industrializados, como a que reduziu o imposto sobre produtos industrializados (IPI).

7 As indústrias maquiladoras realizam atividades manufatureiras de caráter parcial, sendo responsáveis, em suma, pela montagem de produtos manufaturados. Nos anos 60, essas indústrias passaram a fazer parte do plano de desenvolvimento do México e ganharam força, principalmente, a partir dos anos 80 , quando houve um aumento significativo das indústrias maquiladoras na estrutura produtiva mexicana.

8 Cypher (2001) indica que as maquiladoras tendem a reduzir o dinamismo do mercado interno, pois apesar de promover a oferta de um considerável número de empregos, essas indústrias pagam baixos salários, de modo a inviabilizar o acesso dos trabalhadores a produtos de elevado grau tecnológico.
} 


\subsection{Evidências da desindustrialização na ótica do emprego industrial}

A literatura clássica traz a participação do emprego industrial no emprego total como o indicador pioneiro da análise do processo de desindustrialização. Rowthorn e Ramaswany (1999) indicam que uma queda nessa relação está fortemente associada à ocorrência da desindustrialização em determinado país/região. A tabela 2 mostra o comportamento do emprego industrial dos países selecionados.

Em todos os casos, a queda na participação do emprego industrial não foi contínua, apresentando crescimento em alguns momentos. Em termos gerais, houve uma relativa estabilidade nas variações. Contudo, essa foi mantida pela indústria extrativa e pelos segmentos da indústria manufatureira especializados na produção de bens de baixo valor tecnológico, em especial os intensivos em recursos naturais, que expandiram sua participação no decorrer dos anos 2000.

Tabela 1 - Emprego industrial de 2000-2014 (\% do emprego total)

\begin{tabular}{l|c|c|c|c}
\hline \multirow{2}{*}{ Período } & \multicolumn{4}{|c}{ País } \\
\cline { 2 - 5 } & Brasil & México & Argentina & Chile \\
\hline 2000 & 21,1 & 26,9 & 22,6 & 23,3 \\
\hline 2003 & 20,8 & 24,9 & 21,6 & 23,3 \\
\hline 2006 & 21,3 & 25,7 & 23,7 & 23,2 \\
\hline 2009 & 22,1 & 23,8 & 23,1 & 54,2 \\
\hline 2012 & 23,8 & 23,5 & 23,9 & 23,8 \\
\hline 2014 & 22,9 & 25,5 & 24,5 & 23,4 \\
\hline
\end{tabular}

Fonte: Elaborado pelo autor com base nos dados do World Bank

Ao considerar somente a indústria manufatureira (olhar gráficos 5, 6, 7 e 8), o resultado observado é outro. Nesse caso, a tendência da relação emprego industrial/ emprego total é de queda em todos os países selecionados. No México, em virtude da presença das manufaturas maquiladoras em seu território, essa queda vem se dando de forma mais lenta, convergindo com o resultado observado no indicador de valor adicionado da indústria. Nos casos do Brasil, Argentina e Chile, o processo vem evoluindo de forma mais agressiva, com uma tendência a queda mais acentuada. $\mathrm{O}$ comportamento deste indicador fortalece o argumento de que os países selecionados estão passando por um processo de desindustrialização, mas de forma heterogênea.

Gráfico 5 - Emprego na indústria manufatureira do Brasil (\% participação)

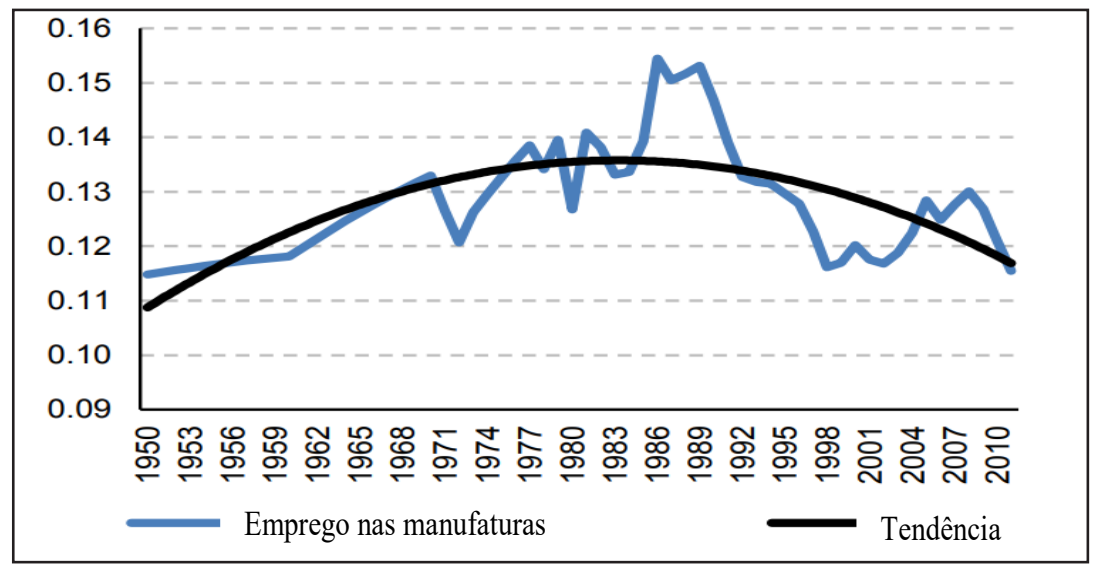

Fonte: Castillo e Martins Neto (2016) 
Gráfico 6 - Emprego na indústria manufatureira do México (\% participação)

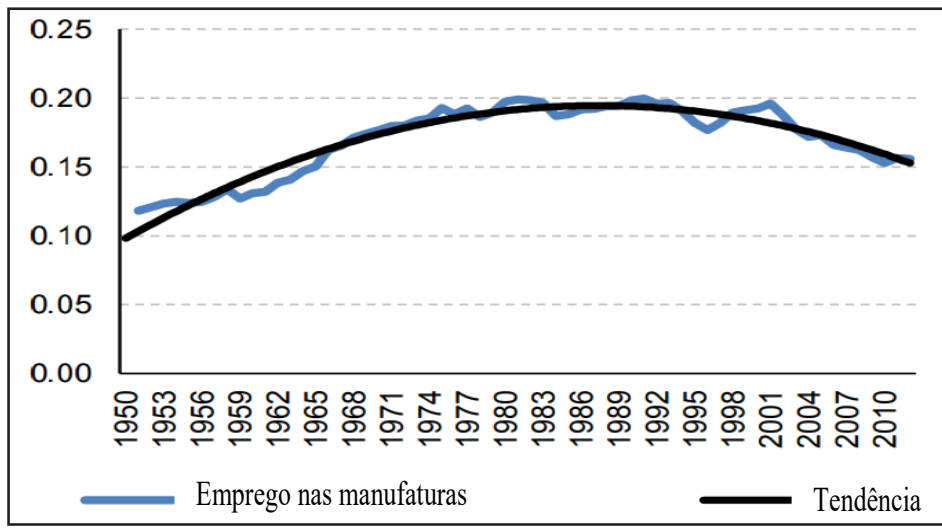

Fonte: Castillo e Martins Neto (2016)

Gráfico 7 - Emprego na indústria manufatureira da Argentina (\% participação)

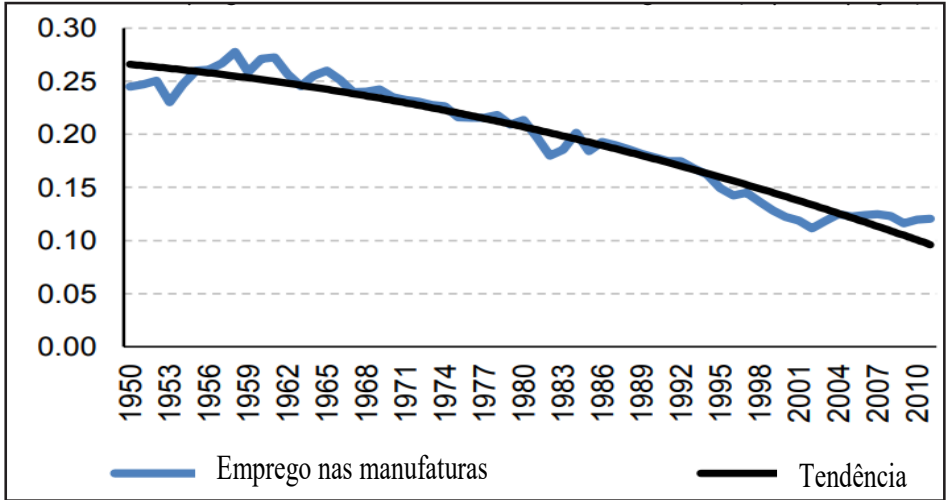

Fonte: Castillo e Martins Neto (2016)

Gráfico 8 - Emprego na indústria manufatureira da Chile (\% participação)

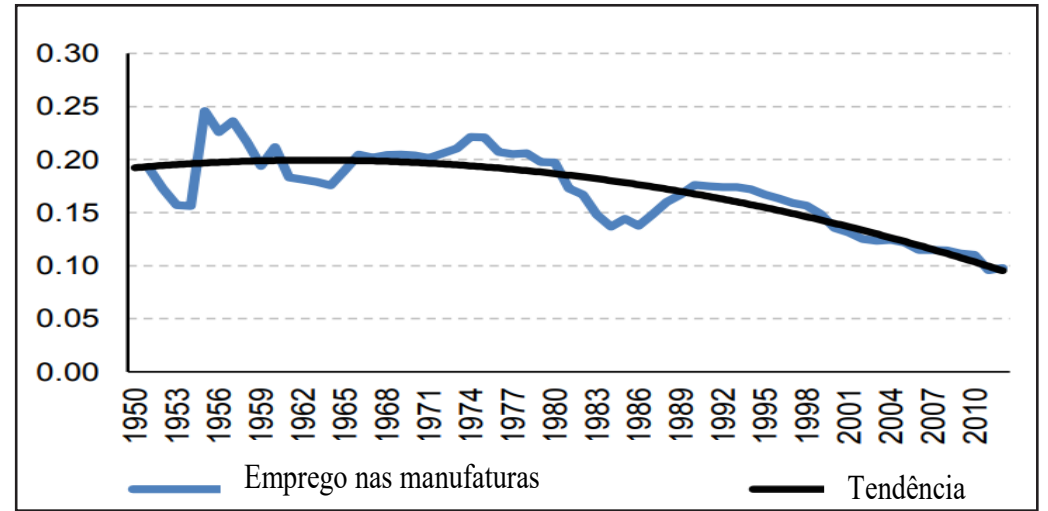

Fonte: Castillo e Martins Neto (2016)

A mão de obra remanescente passou a se direcionar, principalmente, para o setor de serviços, que teve um aumento em sua participação relativa no emprego total, assim como no produto da economia. Todavia, diferente do caso dos países desenvolvidos, nos países latino-americanos o setor de serviços, em sua maioria, paga baixos salários e apresenta baixa produtividade, o que estimula o efeito composição negativo, responsável por reduzir o nível de produtividade total da economia. O resultado sugere, portanto, que a desindustrialização que esses países vêm passando é prematura, visto que o efeito composição negativo é uma característica intrínseca a esses casos. 


\subsection{O comércio internacional e seus apontamentos sobre o processo de desindustrialização}

Por fim, a análise do comércio internacional também aparece como um importante indicador do processo de desindustrialização, à medida que o desempenho da balança comercial dos setores traz elementos que fundamentam a ocorrência do processo. $\mathrm{O}$ gráfico 9 mostra a evolução das exportações de bens manufaturados dos países selecionados no período da análise em questão.

Por meio deste é possível observar que, até 2008, houve um crescimento das exportações de bens manufaturados em todos os países selecionados, sobretudo no México que, dentre os países em questão, é o que apresenta maior participação no comércio internacional em decorrência, principalmente, da dinâmica das maquiladoras. Com a crise do subprime, as exportações de manufaturados caem 2009, voltando a crescer nos anos seguintes, mas em níveis inferiores aos apresentados antes da crise, com exceção da Argentina que passa a apresentar um crescimento exponencial, embora ainda muito inferior ao do Brasil e do México.

Gráfico 9 - Evolução das exportações de manufaturados de 2000-2014 (US\$ Bilhões)

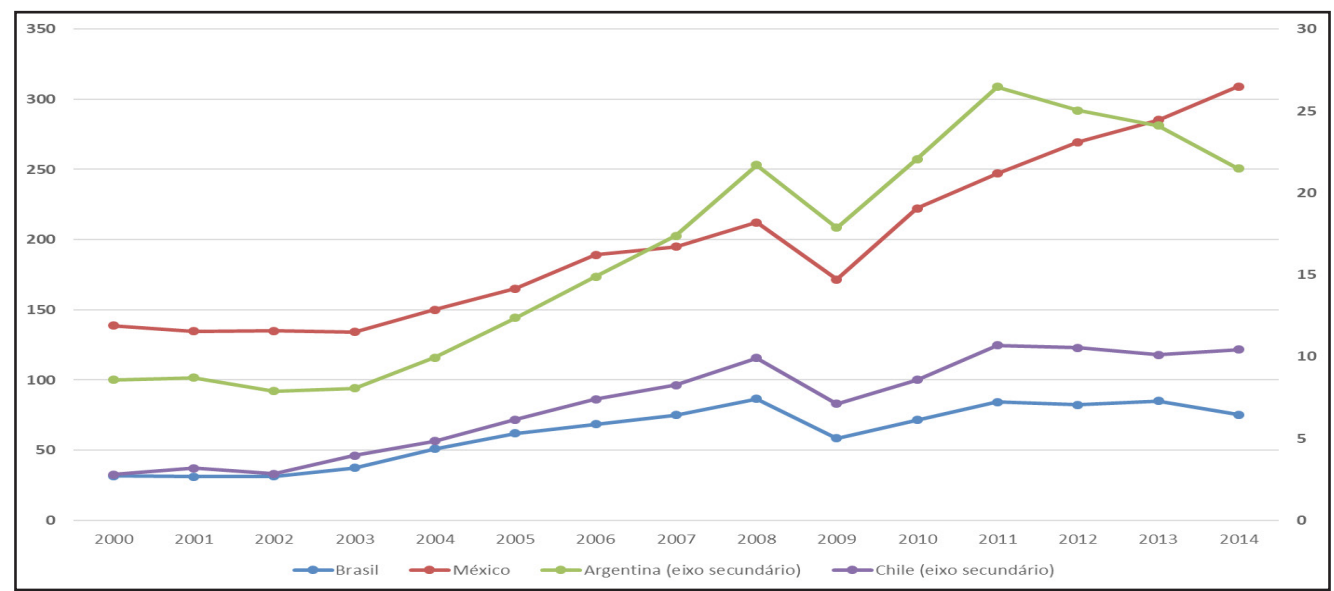

Fonte: Elaborado pelo autor com base nos dados do Wits

Contudo, o comportamento das exportações não é suficiente para capturar o desempenho da indústria no comércio internacional. Ao falar de desempenho dos setores no contexto do comércio internacional, faz-se necessário analisar o saldo da balança comercial destes. O gráfico 10 mostra o resultado da balança comercial da indústria manufatureira dos países em questão.

Gráfico 10: Saldo da balança comercial de produtos manufaturados de 2000-2014 (US\$ Bilhões)

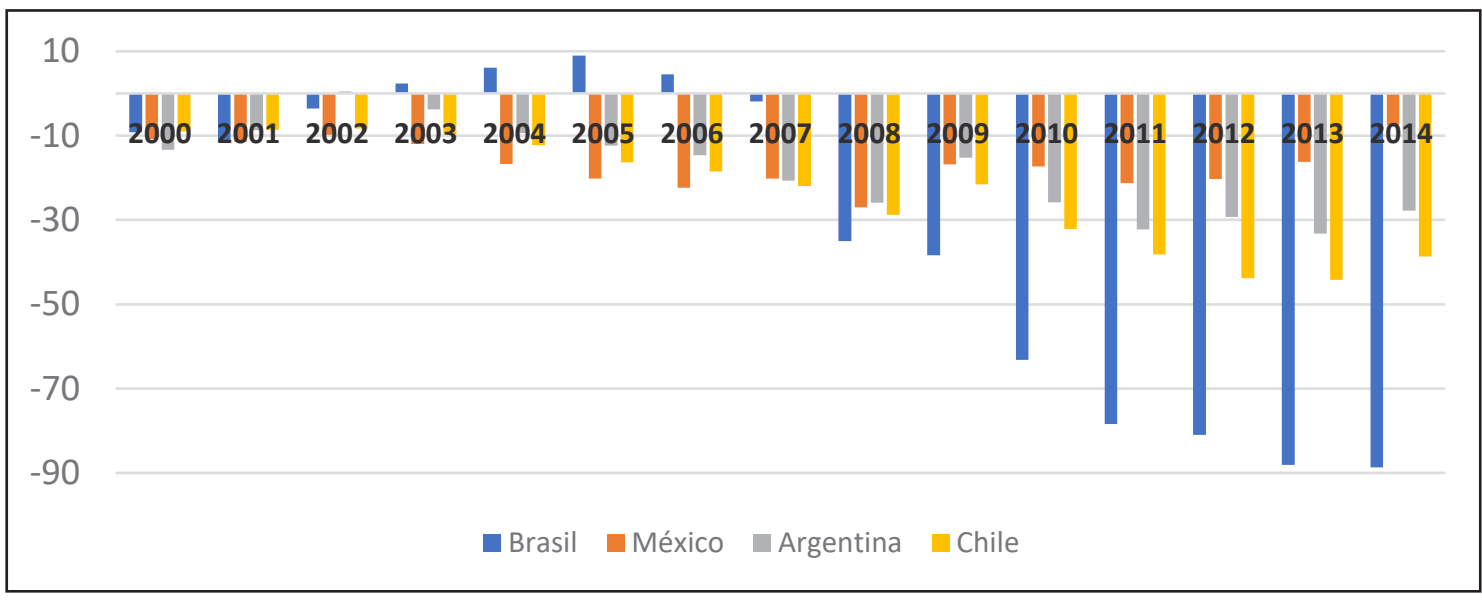

Fonte: Elaborado pelo autor com base nos dados do Wits

Com exceção do Brasil, que apresentou superávit durante 4 anos consecutivos (2003-2006), e da Argentina, que apresentou saldo positivo em 2002, os demais países apresentaram déficit na balança de produtos manufaturados em todos os anos da análise. Após os 4 anos de resultados positivos, o Brasil passou apresentar déficits crescentes, que a partir de 2008 já eram superiores aos dos demais países.

O resultado mostra que a evolução crescente das exportações não foi suficiente para compensar a evolução cavalar nas 
importações de manufaturados. O saldo negativo desta balança impacta negativamente na balança comercial total e, em última instância, no balanço de pagamentos, tornando-o mais fragilizado. Por outro lado, esse desempenho evidencia a perda da competitividade da indústria desses países frente a acirrada concorrência internacional, que se deu em função, especialmente, da forte apreciação cambial que aparece como reflexo dos sintomas da doença holandesa.

Observa-se, portanto, que diante do acelerado processo de globalização, os países latino-americanos selecionados mostraram-se incapazes de se ater de políticas/instrumentos que viessem a neutralizar ${ }^{9}$, mesmo que parcialmente, os efeitos da doença holandesa.

Cabe sobrelevar que os produtos primários e de baixo valor tecnológico ganharam força na pauta exportadora desses países ${ }^{10}$, apresentando saldos que impactaram positivamente na balança comercial total. A expansão desses produtos nas exportações sugere que o processo de desindustrialização que vem afetando essas economias configura-se precoce, haja visto que vem sendo acompanhado por um processo de reprimarização da pauta exportadora.

\section{Considerações finais}

Nas últimas décadas, o processo de desindustrialização situou-se no centro dos debates em torno da estrutura produtiva dos países latino-americanos. As mudanças estruturais com a chegada da onda neoliberal trouxeram consigo a hipótese que a indústria dessa região estava comprimindo sua participação na economia, em um processo diferente do observado na primeira metade do século XX.

A análise de indicadores industriais - participação do valor adicionado da indústria no PIB, participação do emprego industrial no emprego total e balança comercial de manufaturados -, no período de 2000-2014, trouxe elementos que tornaram lúcidas as afirmações de que a indústria vem reduzindo sua participação na economia dos países latino-americanos selecionados.

As variações negativas, mesmo que não contínuas, da participação relativa do valor adicionado da indústria no PIB foi o primeiro elemento que confirmou a ocorrência do processo de desindustrialização. O indicador evidenciou que, assim como no início do processo de industrialização, a desindustrialização vem se dando de forma heterógena entre os países selecionados. No México, apesar de algumas questões negativas, as manufaturas maquiladoras têm retardado a ocorrência da desindustrialização na economia mexicana. Nos demais países, a evolução deste processo evidenciou-se bem mais agressiva.

O comportamento do indicador de emprego industrial fortaleceu o argumento da ocorrência da desindustrialização. Ao circunscrever o exame a participação do emprego da indústria manufatureira, esse resultado foi melhor evidenciado, apresentando uma tendência de queda em todos os países em questão. Assim como o de valor adicionado, o indicador de emprego industrial apontou que no caso mexicano a perda de importância da indústria na economia está se dando de forma mais lenta.

Por fim, o comportamento da balança comercial de manufaturados trouxe elementos que confirmaram a conclusão dos indicadores anteriores. As exportações de manufaturados, em suma, apresentaram significativo crescimento, principalmente no México, com inflexão no pós-2008 em decorrência da crise do subprime. Contudo, ao considerado o saldo, observa-se que houve déficit na balança de manufaturados em todos os anos considerados na análise, com exceção do caso brasileiro, que apresentou superávit no quadriênio de 2003-2006, e do argentino em 2003. Em última instância, o câmbio apreciado justifica significativa parte da trajetória descendente do saldo desta balança. Em meio a crescente concorrência internacional, o câmbio apreciado deteriorou a competitividade da indústria desses países, contribuindo, portanto, para a ocorrência do processo de desindustrialização.

Em suma, pôde-se observar que os países selecionados vêm passando por um processo de desindustrialização que se configura precoce - à medida que a pauta exportadora vem se reprimarizando - e heterogêneo, assim como o início do processo de industrialização.

\section{Referências}

Castillo, M., and A. Martins Nieto. Premature deindustrialization in Latin America. Series: Production

Development. Vol. 205. Santiago: CEPAL. 2016

CLARK, C. The conditions of economic progress. London: Macmillan, 1957.

CYPHER, James M. México since NAFTA: elite delusions and the reality of decline. In: New Labor Forum. Sage CA: Los Angeles, CA: SAGE Publications, 2011. p. 61-69.

9 Nos anos precedentes a chegada da onda neoliberal na América Latina algumas políticas adotadas, como as tarifas à importação, neutralizavam, ou pelo menos retardavam, os efeitos da doença holandesa.

10 Ver mais em World Integrated Trade Solution (WITS). 
DEPARTAMENTO INTERSINDICAL DE ESTATÍSTICA E ESTUDOS SOCIOECONÔMICOS - DIEESE.

Desindustrialização: conceito e situação do Brasil. Nota Técnica n. 100, jun. 2011.

FILGUEIRAS, L. A natureza do atual padrão de desenvolvimento brasileiro e o processo de desindustrialização. Centro Celso Furtado e BNB, Rio de Janeiro, 2012.

FURTADO, Celso. Formação econômica do Brasil. São Paulo: Editora Nacional, 1982.

MARINI, Ruy Mauro. Dialética da Dependência. Petrópolis: Vozes, 2000.

MOREIRA, Carlos Américo Leite; DE MAGALHÃES, Emanuel Sebag. Um novo padrão exportador de especialização produtiva? Considerações sobre o caso brasileiro. Revista da Sociedade Brasileira de Economia Política, n. 38, 2014.

NAJBERG, Sheila; VIEIRA, Solange Paiva. Demanda setorial por trabalho: uma aplicação do modelo de geração de emprego. Pesquisa e planejamento Econômico, v. 48, n. 1, 1997.

NASSIF, A. Há evidências de desindustrialização no Brasil? Revista de Economia Política, São Paulo, v. 28, n.1, p. 72-96, mar. 2008.

OREIRO, José Luis; FEIJÓ, Carmem A. Desindustrialização: conceituação, causas, efeitos e o caso brasileiro. Revista de economia política, v. 30, n. 2, p. 219-232, 2010.

OSORIO, Jaime. América Latina: o novo padrão exportador de especialização produtiva-estudo de cinco economias da região. Padrão de reprodução do capital: contribuições da teoria marxista da dependência. São Paulo: Boitempo, p. 103-133, 2012.

PALMA, José Gabriel. Quatro fontes de desindustrialização e um novo conceito de doença holandesa. In: Conferência de industrialização, desindustrialização e desenvolvimento. Federação das Indústrias do Estado de São Paulo, 2005

ROWTHORN, R; RAMASWANY, R. Growth, Trade and Deindustrialization. IMF Staff Papers, vol. 46, n.1, 1999.

SCHYMURA, Luiz; PINHEIRO, M. C. Política industrial brasileira: motivações e diretrizes. O futuro da indústria no Brasil: desindustrialização em debate. Rio de Janeiro: Civilização Brasileira, p. 81-94, 2013.

TAVARES, Maria da Conceição. Acumulação de Capital e Industrialização no Brasil. 2 ed. Campinas: UNICAMP, 1986.

THORP, Rosemary. Progresso, pobreza e exclusão: uma história econômica de América Latina no Século XX. Inter-American Development Bank, 1998.

TREGENNA, F. Characterizing deindustrialization: an analysis of changes in manufacturing employment and output internationally. Cambridge Journal of Economics, v. 33, 2009. 